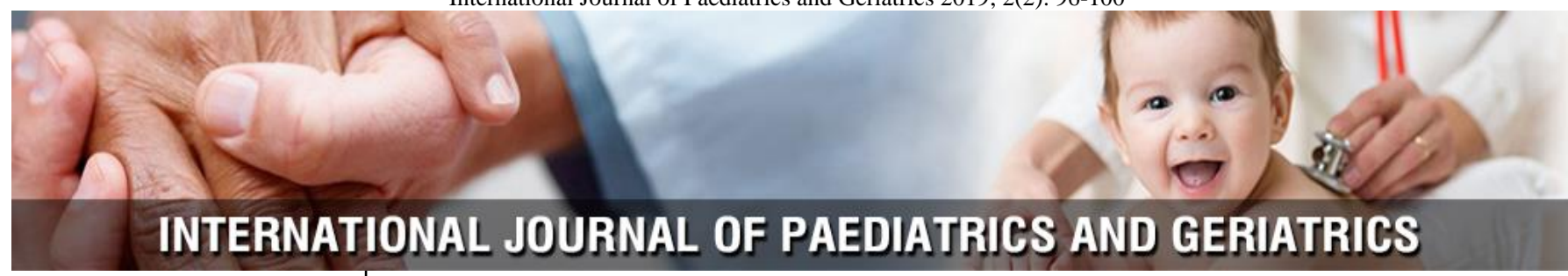

P-ISSN: 2664-3685

E-ISSN: 2664-3693

www.paediatricjournal.com

IJPG 2019: 2(2): 96-100

Received: 17-05-2019

Accepted: 19-06-2019

Dr. Mahesh Bhagavati

Assistant Professor,

Department of Pediatrics,

KIMS, Koppal, Karnataka,

India

Dr. Basavanthappa SP Professor and HOD,

Department of Pediatrics,

Basaveshwara Medical College,

Chitradurga, Karnataka, India

Dr. Pooja V

Resident, Department of

Pediatrics, Basaveshwara

Medical College, Chitradurga,

Karnataka, India
Corresponding Author: Dr. Basavanthappa SP Professor and HOD, Department of Pediatrics, Basaveshwara Medical College, Chitradurga, Karnataka, India

\section{A study of complications in dengue fever among paediatric patients}

\author{
Dr. Mahesh Bhagavati, Dr. Basavanthappa SP and Dr. Pooja V
}

DOI: $\underline{\text { https://doi.org/10.33545/26643685.2019.v2.i2b.41 }}$

\begin{abstract}
The first major epidemics of severe and fatal form of disease, dengue hemorrhagic fever (DHF), occurred in Southeast Asia as a direct result of this changing ecology. The dramatic global geographic expansion during the last 25 years of $20^{\text {th }}$ century, epidemic DF/DHF occurred, facilitated by unplanned urbanization in tropical developing countries, modern transportation, lack of effective mosquito control and globalization. During $21^{\text {st }}$ Century, epidemic DF/DHF is one of the most important infectious disease affecting tropical urban areas. It has been estimated that $50-100$ million of dengue infections, 5,00,000 cases of DHF were hospitalized and 20,000 - 25,000 deaths occurred mainly in children. Detailed history of patients with dengue and NS1 positive or IgM positive serological findings were enrolled into the study after obtaining parental consent. The presenting signs and symptoms that were observed among the cases who meet the inclusion criteria are: fever, headache, retro orbital pain, myalgia, arthralgia, appearance of rashes, any bleeding manifestation (epistaxis, melena, hematemesis), decreased urinary output, breathlessness and yellowish discoloration of eyes. About $73.1 \%$ of the cases without complications were diagnosed as DHF grade I, $26.9 \%$ as grade II and none as grade III in this study. The patients with complications had noted that $7.4 \%$ were diagnosed as grade I, $88.9 \%$ as grade II and $3.7 \%$ as grade III in this study at the time of admission.
\end{abstract}

Keywords: Complications, dengue fever, DHF

\section{Introduction}

Dengue is a disease that comes from Spanish word for a Swahili phrase 'ki denga pepo' meaning cramp like seizure caused by an evil spirit. The first ever case was recorded during the year 992 AD by a Chinese encyclopedia. Batavia, Java in 1779 and Philadelphia, USA in 1780 were earliest reported epidemics. The first case was reported in 1789 and attributed to Benjamin Rush who termed it as Break Bone Fever because of myalgia and arthralgia associated with it. The reports of dengue fever outbreaks were made from everywhere especially in tropical and subtropical areas of the world during the $19^{\text {th }}$ Century ${ }^{[1]}$.

Royal College of Physicians of London first accepted the standard usage of term dengue in 1869. The evidence of A. Aegypti as the vector of the disease was first published by Bancroft in 1906 and confirmed by Cleland, Bradley and Mc Donald in 1916 and Siler et al. in 1926 at Philippines ${ }^{[2]}$.

With the expansion of the global shipping in the $18^{\text {th }}$ and $19^{\text {th }}$ century, port cities were urbanized, creating ideal conditions for the principal vector mosquito, Aedes Aegypti. The mosquitoes and the viruses spread to new Geaographic areas resulting in major epidemics since there was dispersal by sailing ship for long intervals of $10-40$ years between the epidemics. Increased transmission and hyperendemicity was noted due to rapid urbanization in South East Asia after World War II. The first major epidemics of severe and fatal form of disease, dengue hemorrhagic fever (DHF), occurred in Southeast Asia as a direct result of this changing ecology. The dramatic global geographic expansion during the last 25 years of $20^{\text {th }}$ century, epidemic DF/DHF occurred, facilitated by unplanned urbanization in tropical developing countries, modern transportation, lack of effective mosquito control and globalization. During $21^{\text {st }}$ Century, epidemic DF/DHF is one of the most important infectious disease affecting tropical urban areas. It has been estimated that $50-100$ million of dengue infections, 5,00,000 cases of DHF were hospitalized and 20,000 - 25,000 deaths occurred mainly in children ${ }^{[3]}$.

Dengue fever (DF) and Dengue Hemorrhagic fever (DHF) is now one of the most important public health problems in tropical developing countries and also has a major epidemic and social impact ${ }^{[4]}$. 
The literature available shows that, around 3.6 billion people are living mainly in urban areas of tropical and subtropical regions estimated to be at risk of acquiring the dengue viral infection in the World. The reported problem may vary, approximately 50 million to 200 million dengue infections, 500,000 episodes of severe dengue (DHF/DSS) and over 20,000 dengue related deaths occur annually. A recent estimates had shown that 390 million dengue infections occur every year, of which 96 million manifest clinically. DHF is a leading case of hospitalization specially in children in South East Asia. Some countries including Vietnam have shown high attack rates while the rates have fallen in Thailand. The case fatality rates in most of the counties have fallen to less than $1 \%$ where in some countries still exceed $4 \%$ due to late admission to hospital, when the disease is in advanced stage. A successful vector control programme has led to the gradual decline in the incidence of dengue in countries such as Singapore and Malaysia since $1994^{[5]}$.

In India, the occurrence of major disease outbreaks has been reported over last few years. The reliable data on exact problem of the disease is lacking. Some smaller outbreaks may go unnoticed or underreported. In 1996, the first major outbreak of dengue fever in recent memory occurred in New Delhi where more than 10,000 cases and 400 deaths has been reported.

The reports from India suggest that, the disease is not limited to particular region. It has assumed pan - India proportions especially reported from northern states of Haryana, Punjab and Uttar Pradesh: southern states of Andhra Pradesh, Tamil Nadu and Karnataka; western states of Gujarat and Rajasthan and eastern states of West Bengal. The case fatality is above $1 \%$ over last 10 years ${ }^{[6]}$.

The literature available suggests that, DEN - 2 serotype was observed in 1996 but all serotypes have been observed in 2003 outbreak in north India. The 2005 outbreak in Delhi was mainly due to DEN - 3 serotype. Outbreak 2003 has reported greater mortality than in 1996 which can be attributed to difference in serotypes. The Indian Aedes Aegypti species tends to be more susceptible for DEN - 2 virus than its American counterpart.

\section{Methodology}

A cross sectional study was undertaken in the Department of Paediatrics of Medical College and Hospital, among 250 cases presenting with fever for 2 to 7 days from the outpatient and inpatients departments over period of 20 months. The calculated sample size was 250 cases.

Detailed history of patients with dengue and NS1 positive or IgM positive serological findings were enrolled into the study after obtaining parental consent. The presenting signs and symptoms that were observed among the cases who meet the inclusion criteria are: fever, headache, retro orbital pain, myalgia, arthralgia, appearance of rashes, any bleeding manifestation (epistaxis, melena, hematemesis), decreased urinary output, breathlessness and yellowish discoloration of eyes.

Cases were followed up throughout the hospital stay for the onset of complications or until recovery. A detailed laboratory evaluation consisting of $\mathrm{Hb} \%$ estimation, Differential count, platelet count, ESR, urine dipstick, dengue serology (done by CARD test, confirmed by ELISA), Widal test, Rapid diagnostic test for Malaria Parasite, C3 levels was done for all the cases during the time of admission. Platelet count and Haematocrit were monitored on daily basis. ECHO, ECG, LFT, CXR and USG abdomen were conducted among the patients with complications.

The data was compiled by using Microsoft (MS) excel work sheet and analysed using Statistical Package for Social Services (SPSS software version 20.0)

All characteristics were summarized descriptively. For continuous variables, the summary statistics of $\mathrm{N}$, mean, Standard deviation about the arithmetic mean were used. For categorical data, the number and percentage were used to summarise.

Appropriate statistical tests like Chi square test for proportions and Independent sample $\mathrm{T}$ test for continuous variables were used to assess the significant difference. If $\mathrm{P}$ value is $<0.05$, then the test was considered to be statistically significant.

\section{Results}

Table 1: Distribution of the study group according to USG abdomen and complications

\begin{tabular}{|c|c|c|c|}
\hline \multirow{2}{*}{$\begin{array}{c}\text { USG } \\
\text { abdomen }\end{array}$} & No n (\%) & Yes n (\%) & \multirow{2}{*}{$\begin{array}{c}\text { Total } \\
\text { n (\%) }\end{array}$} \\
\cline { 2 - 3 } Normal & $204(91.5)$ & $23(85.2)$ & $227(90.8)$ \\
\hline Abnormal & $19(8.5)$ & $4(14.8)$ & $23(9.2)$ \\
\hline Total & $223(100)$ & $27(100)$ & $250(100)$ \\
\hline
\end{tabular}

$\chi^{2}$ Value $=1.142 \mathrm{df}=1 \mathrm{P}$ value, $\mathrm{Sig}=0.285, \mathrm{NS}$

The USG abdomen was abnormal in $8.5 \%$ of the patients without and $14.8 \%$ of the patients with complications. Gall bladder edema was the most common USG finding in most of the cases. This difference in USG abdomen findings was not statistically significant between the patients without and with complications.

Table 2: Distribution of the study group according to Puffy eye and complications

\begin{tabular}{|c|c|c|c|}
\hline \multirow{2}{*}{ Puffy eye } & \multicolumn{2}{|c|}{ Complications } & \multirow{2}{*}{ Total n (\%) } \\
\hline & No n $(\%)$ & Yes n (\%) & \\
\hline Negative & $192(86.1)$ & \begin{tabular}{l|l}
11 & $(40.7)$ \\
\end{tabular} & $203(81.2)$ \\
\hline Positive & $31(13.9)$ & $16(59.3)$ & $47(18.8)$ \\
\hline Total & $223(100)$ & \begin{tabular}{l|l}
27 & $(100)$ \\
\end{tabular} & $250(100)$ \\
\hline
\end{tabular}

The puffy eye was present in $13.9 \%$ of the patients without and $59.3 \%$ of the patients with complications. This difference in puffy eye was statistically significant between the patients without and with complications.

Table 3: Distribution of the study group according to Sub optimal pulse/ cool periphery/hypotension and complications

\begin{tabular}{|c|c|c|c|}
\hline Suboptimal pulse/ Cool & \multicolumn{2}{|c|}{ Complications } & Total \\
\cline { 2 - 4 } Periphery/Hypotension & No n (\%) & Yes n (\%) & n (\%) \\
\hline Negative & $223(100)$ & $26(96.3)$ & $249(99.6)$ \\
\hline Positive & 0 & $1(3.7)$ & $1(0.4)$ \\
\hline Total & $223(100)$ & $27(100)$ & $250(100)$ \\
\hline
\end{tabular}

$\chi^{2}$ Value $=8.292 \mathrm{df}=1 \mathrm{P}$ value, $\mathrm{Sig}=0.004$, Sig

The suboptimal pulse/ cool periphery/ hypotension was positive in none of the patients without complications and $3.7 \%$ of the patients with complications. This difference was statistically significant between the patients without and with complications. 
Table 4: Distribution of the study group according to increased PCV and complications

\begin{tabular}{|c|c|c|c|}
\hline \multirow{2}{*}{$\begin{array}{c}\text { PCV increased by } \\
\mathbf{2 0 \%}\end{array}$} & \multicolumn{2}{|c|}{ Complications } & \multirow{2}{*}{ Total n (\%) } \\
\cline { 2 - 3 } & No n (\%) & Yes n (\%) & \\
\hline Negative & $192(86.1)$ & $14(51.9)$ & $206(82.4)$ \\
\hline Positive & $31(13.9)$ & $13(48.1)$ & $44(17.6)$ \\
\hline Total & $223(100)$ & $27(100)$ & $250(100)$ \\
\hline
\end{tabular}

$\chi 2$ Value $=19.477 \mathrm{df}=1 \mathrm{P}$ value, $\mathrm{Sig}=0.000, \mathrm{Sig}$

The increased PCV was found in $13.9 \%$ of the patients without and $48.1 \%$ of the patients with complications which was statistically significant.

Table 5: Distribution of the study group according to pleural effusion and complications

\begin{tabular}{|c|c|c|c|}
\hline \multirow{2}{*}{$\begin{array}{c}\text { Pleural } \\
\text { effusion CXR }\end{array}$} & \multicolumn{2}{|c|}{ Complications } & \multirow{2}{*}{$\begin{array}{c}\text { Total } \\
\mathbf{n}(\boldsymbol{\%})\end{array}$} \\
\cline { 2 - 3 } & No n (\%) & Yes n (\%) & $249(99.6)$ \\
\hline Negative & $223(100)$ & $26(96.3)$ & $1(0.4)$ \\
\hline Positive & 0 & $1(3.7)$ & $250(100)$ \\
\hline Total & $223(100)$ & $27(100)$ & 250 \\
\hline
\end{tabular}

$\chi 2$ Value $=8.292 \mathrm{df}=1 \mathrm{P}$ value, Sig $=0.004$, Sig

The pleural effusion was not present in any patients without complications and present in $3.7 \%$ of the patients with complications which was statistically significant.

Table 6: Distribution of the study group according to respiratory distress and complications

\begin{tabular}{|c|c|c|c|}
\hline Respiratory & \multicolumn{2}{|c|}{ Complications } & Total \\
\hline distress(ARDS) & No n (\%) & Yes n (\%) & n (\%) \\
\hline Negative & $223(100)$ & $26(96.3)$ & $249(99.6)$ \\
\hline Positive & 0 & $1(3.7)$ & $1(0.4)$ \\
\hline Total & $223(100)$ & $27(100)$ & $250(100)$ \\
\hline
\end{tabular}

$\chi^{2}$ Value $=8.292 \mathrm{df}=1 \mathrm{P}$ value, $\mathrm{Sig}=0.004, \mathrm{Sig}$

The respiratory distress was present in $3.7 \%$ of the patients with complications which was statistically significant.

Table 7: Distribution of the study group according to GCS and complications

\begin{tabular}{|c|c|c|c|}
\hline \multirow{2}{*}{ GCS } & \multicolumn{2}{|c|}{ Complications } & \multirow{2}{*}{ Total n (\%) } \\
\cline { 2 - 3 } & No n (\%) & Yes n (\%) & \\
\hline Normal & $223(100)$ & $26(96.3)$ & $249(99.6)$ \\
\hline Abnormal & 0 & $1(3.7)$ & $1(0.4)$ \\
\hline Total & $223(100)$ & $27(100)$ & $250(100)$ \\
\hline
\end{tabular}

$\chi^{2}$ Value $=8.292 \mathrm{df}=1 \mathrm{P}$ value, Sig $=0.004$, Sig

The GCS was abnormal in none of the patients without complications and $3.7 \%$ of the patients with complications which was statistically significant.

Table 8: Distribution of the study group according to ICU Stay and complications

\begin{tabular}{|c|c|c|c|}
\hline \multirow{2}{*}{ ICU stay } & \multicolumn{2}{|c|}{ Complications } & \multirow{2}{*}{ Total n $(\boldsymbol{\%})$} \\
\cline { 2 - 3 } & No n $(\boldsymbol{\%})$ & Yes n $(\boldsymbol{\%})$ & \\
\hline 0 days & $223(100)$ & 0 & $223(89.2)$ \\
\hline 1 days & 0 & $26(96.3)$ & $26(10.4)$ \\
\hline 3 days & 0 & $1(3.7)$ & $1(0.4$ \\
\hline Total & $223(100)$ & $27(100)$ & $250(100)$ \\
\hline
\end{tabular}

$\chi^{2}$ Value $=250.0 \mathrm{df}=2$ P value, $\operatorname{Sig}=0.000$, Sig

All the patients without complications were not admitted to ICU and $96.3 \%$ of the cases with complications stayed for 1 day and $3.7 \%$ stayed for 3 days in the ICU.
Table 9: Distribution of the study group according to duration of hospitalization and complications

\begin{tabular}{|c|c|c|c|}
\hline \multirow{2}{*}{$\begin{array}{c}\text { Duration of } \\
\text { hospitalization }\end{array}$} & \multicolumn{2}{|c|}{ Complications } & \multirow{2}{*}{ Total n (\%) } \\
\cline { 2 - 3 } & No n (\%) & Yes n (\%) & \\
\hline 3 Days & $50(22.4)$ & $7(25.9)$ & $57(22.8)$ \\
\hline 4 Days & $36(16.1)$ & $1(3.7)$ & $37(14.8)$ \\
\hline 5 Days & $18(8.1)$ & 0 & $18(7.2)$ \\
\hline More than 5 Days & $119(53.4)$ & $19(70.4)$ & $138(55.2)$ \\
\hline Total & $223(100)$ & $27(100)$ & $250(100)$ \\
\hline
\end{tabular}

$\chi 2$ Value $=6.089 \mathrm{df}=3 \mathrm{P}$ value, $\mathrm{Sig}=0.107, \mathrm{NS}$

The duration of hospitalization in $22.2 \%$ of the cases without complications was 3 days, 4 days in $16.1 \%, 5$ days in $8.1 \%$ and more 5 days in $53.4 \%$ of the cases. The duration of hospitalization was 2 days in $25.9 \%, 3$ days in $3.7 \%$ and 5 days in $70.4 \%$ of the cases which was statistically not significant.

Table 10: Distribution of the study group according to life support and complications

\begin{tabular}{|c|c|c|c|}
\hline \multirow{2}{*}{ Life support } & \multicolumn{2}{|c|}{ Complications } & \multirow{2}{*}{ Total n (\%) } \\
\cline { 2 - 3 } & No n (\%) & Yes n (\%) & \\
\hline Absent & $223(100)$ & $26(88.9)$ & $249(98.9)$ \\
\hline Present & 0 & $3(11.1)$ & $3(1.2)$ \\
\hline Total & $223(100)$ & $27(100)$ & $250(100)$ \\
\hline
\end{tabular}

$\chi^{2}$ Value $=25.079 \mathrm{df}=1 \mathrm{P}$ value, Sig $=0.000$, Sig

The life support was needed in $11.7 \%$ of the cases with complications which was statistically significant.

Table 11: Distribution of the study group according to Mortality and complications

\begin{tabular}{|c|c|c|c|}
\hline \multirow{2}{*}{ Mortality } & \multicolumn{2}{|c|}{ Complications } & \multirow{2}{*}{ Total n (\%) } \\
\cline { 2 - 3 } & No n (\%) & Yes n (\%) & \\
\hline Absent & $223(100)$ & $26(88.9)$ & $249(98.9)$ \\
\hline Present & 0 & $3(11.1)$ & $3(1.2)$ \\
\hline Total & $223(100)$ & $27(100)$ & $250(100)$ \\
\hline
\end{tabular}

$\chi 2$ Value $=25.079 \mathrm{df}=1 \mathrm{P}$ value, $\mathrm{Sig}=0.000, \mathrm{Sig}$

The mortality was present in $11.1 \%$ of the cases with complications in this study which was statistically significant.

Table 12: Distribution of the study group according to DHF grading and complications

\begin{tabular}{|c|c|c|c|}
\hline \multirow{2}{*}{ DHF grading } & \multicolumn{2}{|c|}{ Complications } & \multirow{2}{*}{ Total n (\%) } \\
\hline & Non $(\%)$ & Yes n (\%) & \\
\hline Grade I & $163(73.1)$ & $2(7.4)$ & $165(66.0)$ \\
\hline Grade II & $60(26.9)$ & $24(88.9)$ & $84(33.6)$ \\
\hline Grade III & 0 & $1(3.7)$ & $1(0.4)$ \\
\hline Total & $223(100)$ & \begin{tabular}{l|l|}
27 & $(100)$
\end{tabular} & $250(100)$ \\
\hline
\end{tabular}

About $73.1 \%$ of the cases without complications were diagnosed as DHF grade I, $26.9 \%$ as grade II and none as grade III in this study. The patients with complications had noted that $7.4 \%$ were diagnosed as grade I, $88.9 \%$ as grade II and $3.7 \%$ as grade III in this study at the time of admission.

\section{Discussion}

Dengue fever is a major public health problem especially among the pediatric population. The disease is rampant in tropical and subtropical countries mainly affecting urban 
and sub urban areas. It is a most common mosquito - borne arbor viral infection (single stranded RNA virus) which results in significant morbidity and mortality.

The estimates have shown that, 2.5 billion people are mainly living in urban areas who are under risk of acquiring the infection ${ }^{[1]}$. It has become a leading cause of hospitalization and death especially among the children in the South - East Asia region of WHO over last $10-15$ years following diarrhoea disease and acute respiratory infections ${ }^{[3]}$.

Dengue is caused by a serologically related but antigenically distinct single strand of positive RNA viruses. The literature had shown four different types of serotypes are known cause Dengue infection (DENV through DENV - 4. The virus belongs to flaviviurs family and Aedes Aegypti is the primary mosquito vector but other species of genus Aedes, such as Aedes albopictus can also spread the disease. The clinical spectrum ranges from asymptomatic infection, mild dengue fever (DF), dengue hemorrhagic fever (DHF) or dengue shock syndrome, which is often fatal because of abnormal capillary permeability and plasma leakage. The disease may manifest as myocardiopathy, hepatic failure and neurological disorders. Specific treatment for the dengue is not available till today but only vector control is the main preventive strategy ${ }^{[7]}$.

Plasma leakage due to alteration in microvascular permeability is the pathognomonic feature of the severe DHF. No vaccine and specific antiviral therapy is available for the treatment of $\mathrm{DF} / \mathrm{DHF}$. Hence supportive therapy plays a key role in management of the disease. The dengue virus is often confused with other febrile illness of viral origin which confounds both clinical management and disease surveillance for prevention of viral transmission ${ }^{[8]}$.

The diagnostic tests such as RT- PCR is costly; not sufficiently rapid, such as virus isolation or under field trials including ELISA for NS1 protein of Dengue virus can be used at early stages of illness. Simple haematological or biochemical tests are the need of the hour which can be useful for case management and preventing mortality and morbidity ${ }^{[6]}$.

The radiological techniques including ultrasonography is useful in diagnosing GB wall thickening, Pericholecystic fluid, minimal ascites, pleural effusion, pericardial effusion and hepatosplenomegaly. The ultrasonography was also able to find the abnormality of liver parenchyma which can be due to intraparenchymal and Subcapsular haemorrhages. GB wall thickening in DF can be due to decrease in Intravscualr osmotic pressure ${ }^{[9]}$.

The complications of dengue fever usually happen after the $5^{\text {th }}$ day of illness. The complications of dengue include fluid leak, bleeding, hepatitis, encephalopathy, ARDS especially in paediatric age group and its most important public health problem in tropical developing countries and also have a major economic and social impact ${ }^{[8]}$.

The present study aims at assessing the clinical profile, laboratory parameters and complications of dengue fever and the correlation of laboratory parameters to the complications.

Gall bladder edema was the most common USG finding in most of the cases. In a study by Gupta et al. had shown that ascitis was the main USG finding on the study ${ }^{[10]}$.

The puffy eye was present in $13.9 \%$ of the patients without and $59.3 \%$ of the patients with complications. No studies have compare these findings.

The suboptimal pulse/ cool periphery/ hypotension was positive in none of the patients without complications and $3.7 \%$ of the patients with complications. No study had compared these studies.

The increased PCV was found in $13.9 \%$ of the patients without and $48.1 \%$ of the patients with complications. A study by Gupta et al. had shown that the mean hematocrit was $39.13 \%^{[10]}$.

The pleural effusion was present in $3.7 \%$ of the patients with complications. A study by Dhobale et al. had had shown that, about $42 \%$ had pleural effusion ${ }^{[11]}$. In a study by Gupta et al., $18.2 \%$ had pleural effusion, where $9.7 \%$ had unilateral and $8.5 \%$ had bilateral pleural effusion ${ }^{[10]}$.

The respiratory distress was present in $3.7 \%$ of the patients with complications. No studies have compared these findings.

The GCS was abnormal in $3.7 \%$ of the patients with complications. No studies were available for the comparison of these results.

About $96.3 \%$ of the cases with complications stayed for 1 day and $3.7 \%$ stayed for 3 days in the ICU. No studies were available for comparison of these studies.

The duration of hospitalization was more 5 days in $53.4 \%$ of the without complication cases and $70.4 \%$ of the cases with complications. A study by Dhobale et al. had shown that, about $5-10 \%$ were admitted in the hospital for $6-10$ days [11]

The life support was needed in $11.1 \%$ of the cases with complications. No studies were available for comparison of these findings.

The mortality was present in $11.1 \%$ of the cases with complications in this study. In a study by Gupta et al., the rate mortality was $1 \%$ of the cases which was lower than this study ${ }^{[10]}$.

\section{Conclusion}

About $73.1 \%$ of the cases without complications were diagnosed as DHF grade I and $88.9 \%$ of the patients with complications as grade II in this study.

\section{References}

1. Thein S, Aaskov J, Myint TT et al. Changes in levels of anti-dengue virus IgG subclasses in patients with disease of varying severity. J Med Virol. 1993; 40:1026.

2. Koraka P, Murgue B, Deparis X et al. Elevated levels of total and dengue virus-specific immunoglobulin $\mathrm{E}$ in patients with varying disease severity. J Med Virol. 2003; 70:91-8.

3. Miguez-Burbano MJ, Jaramillo CA, Palmer CJ et al. Total immunoglobulin E levels and dengue infection on San Andres Island, Colombia. Clin Diagn Lab Immunol. 1999; 6:624-6.

4. Malavige GN, Fernando S, Fernando DJ, Senevriathe SL, Dengue viral infections, Postgrad Med J. 2004; 80:588-601.

5. Jain PK, Sharma AK, Agarwal N, Siddiqui MZ, Pawal P, Gaba R, Srivastava S, A prospective clinical study of incidence of hepatorenal and hematological complications in dengue fever and management of symptomatic bleed in Bundelkhand region of Northern India with fresh whole blood, Journal of Infectious diseases and immunity. 2011; 3:7:124-33.

5. Malavige GN, Fernando S, Fernando DJ, Senevriathe SL. Dengue viral infections, Postgrad Med J. 2004; 
80:588-601.

6. Navarrete Espinosa J, Gomez Dantes H, Celis Quintal JG, Vasquez Martnez JL. Clinical profile of dengue hemorrhagic fever in Mexico, Salud Publica Mex. 2005; 47:3:193-200.

7. Pham TB, Nguyen TH, Vu TQH, Nguyen TL, Malvy D. Predictive factors of dengue shock syndrome at the children Hospital No. 1, Ho-chi-Minh City, Vietnam. Bull Soc. Pathol Exot. 2007; 100:43-47.

8. Zoraida I Velasco-Salas, Gloria M Sierra, Diamelis M Guzma' N, Julio Zambrano, Daniel Vivas, Guillermo Comach et al. Wilschut, and Adriana Tami. Dengue Seroprevalence and Risk Factors for Past and Recent Viral Transmission in Venezuela: A Comprehensive Community-Based Study. Am. J Trop. Med. Hyg. 2014; 91(5):1039-48.

9. Gupta V, Yadav TP, Pandey RM et al., Risk factors of dengue shock syndrome in children, J Trop Ped. 2011; 57(6):451-6.

10. Dhobale RV, Gore AD, Waghacha-vare VB, Kumbhar SG, Kadam YR, Dhumale GB. Clinical and Labora-tory Characteristics of Pediatric Dengue Fever Patients in a Ter-tiary Care Hospital. Ntl J Community Med. 2015; 7(1):21-24. 